\title{
Narrativa sobre arte popular: estudo de caso sobre tesauro e exposições permanentes elaboradas pelo Centro Nacional de Folclore e Cultura Popular ${ }^{1}$
}

\author{
Elizabete Mendonça ${ }^{2}$ \\ Universidade Federal de Sergipe
}

\begin{abstract}
RESUMO: Este artigo visa apresentar um estudo das narrativas relacionadas à arte popular elaboradas pelo Centro Nacional de Folclore e Cultura Popular (CNFCP), tendo como objetos de estudo o Tesauro de Folclore e Cultura Popular Brasileira, as exposições permanentes de 1980, 1984 e 1994 e as obras de Boaventura da Silva Filho, componentes dessas três exposições. O Tesauro e as exposições permanentes são aqui considerados como ações de documentação e de difusão vinculadas às políticas públicas, desenvolvidas pelo governo federal, para valorização e salvaguarda das referências culturais populares. Investigar as diretrizes, as categorias privilegiadas e suas (re)conceituações como suportes conceituais que determinam tais ações, assim como o uso de termos relacionados à arte popular como instrumento de representações socioculturais que marcaram a trajetória dos estudos de folclore e de cultura popular, foi o caminho escolhido para analisar os contextos específicos da organização institucional do período dos folcloristas, até 1980, e dos antropólogos e museólogos, a partir de 1982. Com base nessa problematização, pautada na análise das mudanças conceituais e de políticas institucionais do CNFCP, buscou-se estabelecer uma abordagem inter-relacional entre tesauro e exposições permanentes dentro de um "sistema artecultura".
\end{abstract}

PALAVRAS-CHAVE: Tesauro, Exposição, Arte Popular, Centro Nacional de Folclore e Cultura Popular.

ABSTRACT: This paper investigates the narratives related to folk art established by the Brazilian Folklore and Popular Culture National Center (CNFCP - Centro Nacional de Folclore e Cultura Popular). Its objects of study are the Thesaurus of Folklore and Brazilian Popular Culture, the 1980, 1984 and 1994 permanent exhibits, and the works of Boaventura da Silva Filho, which were part of the three exhibits. The thesaurus and the permanent exhibits are here considered documentation and dissemination actions linked to public policies developed by the federal government in order to value and protect popular culture references. In order to analyze the specific contexts of the institutional organization of the folklorists' period, until 1980, and that of the anthropologists and museologists, from 1982 on, the study investigated the guidelines, privileged categories and their (re)conceptualizations as conceptual supports that determined those actions. The investigation also encompassed the use of terms related to folk art as an instrument of sociocultural representations

\footnotetext{
${ }^{1}$ Este artigo é um extrato da tese Tesauro e exposições permanentes de folclore e cultura popular: narrativas sobre arte popular elaboradas pelo Centro Nacional de Folclore e Cultura Popular (19802004[2006]), defendida em 2008, no Programa de Pós-Graduação em Artes Visuais - com ênfase na linha de pesquisa Imagem e Cultura - pela Universidade Federal do Rio de Janeiro. O mesmo foi apresentado na mesa-redonda denominada "Olhares sobre o Museu de Folclore Edison Carneiro" que integrou o Seminário "Destinações da cultura popular em museus" realizado em abril de 2010 pelo CNFCP/Iphan.

${ }^{2}$ Graduada em Museologia pela Universidade Federal do Estado do Rio de Janeiro e Doutora em Artes Visuais pela Universidade Federal do Rio de Janeiro. Professora do Núcleo de Museologia e do Programa de Pós-Graduação em Arqueologia da Universidade Federal de Sergipe. E-mail: elizabete.mendonca@gmail.com
} 
that marked the evolution of folk and popular culture studies. Based on this problematization, guided by the analysis of CNFCP's conceptual and institutional policy changes, the study tried to establish an inter-relational approach to the thesaurus and the permanent exhibits within an 'artculture system'.

KEYWORDS: Tesauro, Exhibition, Folk Art, Centro Nacional de Folclore e Cultura Popular.

\section{Definindo o objeto de estudo}

Os objetos de estudo deste artigo serão o Tesauro de Folclore e Cultura Popular Brasileira $^{3}$ e as exposições permanentes de 1980, 1984 e 1994, elaborados pelo Centro Nacional de Folclore e Cultura Popular/Iphan/MinC (CNFCP). Seu objetivo será refletir sobre a apropriação das categorias artesanato e arte popular pelo Tesauro de Folclore e Cultura Popular Brasileira e suas articulações com as narrativas relacionadas à arte popular construídas nas três exposições permanentes.

0 Tesauro e as exposições permanentes foram considerados como ações de documentação e de difusão vinculadas às políticas públicas, desenvolvidas pelo governo federal, para valorização e salvaguarda das referências culturais populares. Investigar as diretrizes, as categorias privilegiadas e suas (re)conceituações como suportes conceituais que determinam tais ações, assim como o uso de termos relacionados à arte popular como instrumento de representações socioculturais que marcaram a trajetória dos estudos de folclore e de cultura popular, foi o caminho escolhido para analisar os contextos específicos da organização institucional do período dos folcloristas, até 1981, e dos antropólogos e museólogos, a partir de 1982. Com base nessa problematização, pautada na análise das mudanças conceituais e de políticas institucionais do

\footnotetext{
${ }^{3}$ A equipe de desenvolvimento deste tesauro teve um caráter interdisciplinar com participação de profissionais efetivos ou contratados do CNFCP ligados a Biblioteca Amadeu Amaral (BAA), ao Museu de Folclore Edison Carneiro (MFEC) e ao Setor de Pesquisa. A maioria da equipe, bem como a coordenação metodológica, ficou a cargo da BAA - idealizadora da proposta.
} 
CNFCP, buscou-se estabelecer uma abordagem inter-relacional entre tesauro e exposições permanentes dentro de um "sistema arte-cultura" (Clifford, 1994).

Para uma análise comparativa das categorias usadas tanto no tesauro quanto nas exposições, foram privilegiadas quatro obras de Louco, nome adotado pelo artista popular baiano Boaventura da Silva Filho, cujas peças fizeram parte dessas três exposições.

\title{
0 recorte temático no objeto de estudo
}

Na definição da UNESCO, Tesauro representa

\begin{abstract}
um vocabulário controlado e dinâmico de termos relacionados semântica e genericamente cobrindo um domínio específico de conhecimento, [funcionando como] um dispositivo de controle terminológico usado na tradução da linguagem natural dos documentos, dos indexadores ou dos usuários numa linguagem do sistema (linguagem de documentação, linguagem de informação) mais restrita, [permitindo assim maior comunicação] (Unesco, 1973: 6 apud CNFCP, 2004).
\end{abstract}

Este instrumento terminológico de indexação tem um caráter inédito nas áreas de conhecimento denominadas folclore e cultura popular brasileira, constituindo-se em importante ferramenta para a organização dos conteúdos temáticos dessas áreas, "possibilitando maior agilidade e eficácia no tratamento e recuperação da informação" (CNFCP, 2004).

Os termos que me propus estudar fazem parte da publicação, em cd-rom, dos resultados da primeira etapa do projeto, lançada em 19 de maio de 2004, durante as comemorações da Semana Internacional de Museus, bem como a sua revisão presente numa segunda versão, lançada em 2006. A segunda versão hoje está disponível no site da instituição. 
É importante frisar que, embora a terminologia aplicada no Tesauro se constitua a partir de diferentes domínios que caracterizam o folclore e a cultura popular, tornou-se necessário fazer um corte temático privilegiando-se, dentre os termos associados à arte popular, aqueles que dizem respeito ao indivíduo produtor (Artesão e Artista popular), ao produto (Objeto artesanal) e ao processo (Técnica artesanal). A escolha desses quatro termos justifica-se pelo fato de estarem diretamente associados às categorias Arte e Técnica, utilizadas como classes nos sistemas classificatórios criados anteriormente pela instituição.

É importante destacar que, se por um lado, a Biblioteca Amadeu Amaral (BAA) foi o setor responsável pela coordenação de conteúdo, e que com base em seu acervo e nas experiências anteriores de elaboração de classificações contribui para a classificação e conceituação dos termos, por outro lado, foi o Museu de Folclore Edison Carneiro (MFEC) que por meio da constituição do seu acervo propiciou a inclusão de todos os termos referentes aos artefatos.

Nas exposições permanentes, o foco foi centrado nos núcleos expositivos denominados Artesanato, Indivíduo e Coletividade e Arte que integraram, respectivamente, as mostras inauguradas em 1980, 1984 e 1994. Em todas, foram destacadas as obras de Louco, denominadas Oxalá Cristo Grande, Painel dos arrependidos, Cabeças entalhadas em raiz e Ceia.

Esta abordagem comparativa entre as diretrizes, categorias privilegiadas, apropriações, mudanças conceituais e sua aplicação na classificação das obras de Louco, fundamenta a suposição de que tanto um tesauro quanto uma exposição são formas de reafirmação de conceitos e suporte de representações socioculturais que refletem o papel do CNFCP na utilização, conceituação e articulação dos termos associados à arte popular. 


\section{Fronteiras terminológicas: as formas de apresentação dos conceitos associados ao domínio da arte}

Neste artigo não está sendo trabalhado a definição de conceitos mas as narrativas sobre arte popular. Neste contexto, é comum apenas ser associada a vinculação da categoria artesanato as ações desenvolvidas pelos folcloristas, considerando que a ideia de produção artística individualizada no contexto dos estudos de folclore era desconsiderada ou desvalorizada. Entretanto, textos comprovam que esta premissa é equivocada. Existem várias referências, exposições temporárias, etc. que incluem ações efetivas de pesquisa e de valorização no campo da arte. 0 importante, neste contexto, é buscar entender o que eles consideravam arte popular? Como a exposição permanente de 1980 reflete a compreensão que tinham desse campo. Além de estabelecer um paralelo entre esta exposição e as posteriores, buscando assim entender se existem diferenças entre o que era representativo do campo da arte na perspectiva folclorista e o que hoje é pela perspectiva antropológica. Estas perspectivas em questão são dadas pelos agentes do que Clifford (1994) chama de "sistema arte-cultura".

James Clifford, ao explicar o sistema arte-cultura, evidencia os processos institucionais e ideológicos envolvidos nos processos de apropriação material e simbólica dos objetos, assim como acumulação e classificação dos mesmos. Entretanto, o autor ressalta que os parâmetros de tais processos não são universais e que as mudanças de classificação fazem parte do processo de transformação dos pressupostos teóricos, da rede institucional de exposições e de publicações. Para Duvignaud (1994) as categorias classificatórias não se reduzem à simples constatação de uma diferença entre elas: ultrapassam, seguidamente, a ideia que fazem desses sistemas.

Nesta perspectiva, iniciando pela perspectiva dos folcloristas foram analisados alguns exemplos do uso da categoria arte, começando pela proposta de Museu Ergológico Brasileiro, de Gustavo Barroso (1945). Na classificação dos objetos 
citada nessa publicação, Barroso divide a nomenclatura de todas as classes com a palavra arte (arte da habitação, arte naval, arte da pescaria, arte da caça, arte do preparo do alimento, artes domésticas, artes do artesanato), entretanto a categoria é equiparada as habilidades, os ofícios, que representariam a "origem, a evolução $e$ as finalidades" de um saber popular específico. Nesta perspectiva, o autor não trabalha a ideia de particularidade da produção de um indivíduo, ele enfoca somente o coletivo.

Dialogando com essa perspectiva, a proposta de classificação decimal do Folclore (Salles, 197) aplicada durante anos na Biblioteca Amadeu Amara também demonstra esta mediação e ambiguidade na própria nomenclatura da classe específica do universo que se estuda nessa apresentação: Artes e Técnicas. Sob o número 398.6, esta classe é definida como "Ergologia folclórica. Incluía técnicas e indústrias populares, artesanato, etc.". As sub-classes (ou termos) são Generalidades; Aspectos gerais; Arquitetura; Escultura e ex-votos; Cerâmica; Desenho. Pintura e decoração. Xilogravura; Tecnologia; Manufaturas; Instrumentos musicais; Máquinas e instrumentos de trabalho. Percebe-se que estas nomenclaturas valorizam as técnicas e objetos. Os demais termos reafirmam a aceitação da coletividade.

Analisando textos, relatórios, listagens de peças e exposições da Campanha de Defesa do Folclore Brasileiro, percebe-se que esta postura tão voltada a uma compreensão de arte restrita a habilidade, sem destaque para a individualização, não é tão fechada. Existe sempre uma tensão entre o que é o artesanato anônimo e a valorização do caráter individualizado. A começar por dois trechos da Carta do Folclore de 1951: o primeiro aborda as manifestações folclóricas não anônimas desde vinculadas a "aceitação coletiva [...] e essencialmente popular" como fatos folclóricos, o segundo afirmar a importância da criação de museus folclóricos "dedicado ao folclore e às artes populares". Um documento redigido provavelmente no dia da criação do Museu também o trata como "museu de arte e 
técnicas populares". Está sempre nítida a dialética e a dicotomia entre Técnica e Arte.

A mesma controvérsia é encontrada se confrontarmos três documentos (datados de 1963, 1965 e 1972) relativos às exposições temporárias realizadas pela Campanha de Defesa do Folclore Brasileiro. Os dois primeiros documentos são relativos ao período anterior a criação do Museu, entretanto, já citam o termo Arte popular. No primeiro documento, de 1963, são listados 34 itens agrupados pelo nome do estado ou da localidade de origem, indicando apenas o nome de alguns autores: Ernestina (de Recife), Mestre Nosa (de Juazeiro) e Chico Santeiro (de Natal). No segundo documentos, de 1965, 22 itens são listados aleatoriamente, porém ao contrário do anterior o nome do estado ou da localidade não está expresso em todos (nem na maioria) e a indicação de autoria continua estando presente apenas em algumas peças, sendo eles: Zé Caboclo (de Caruaru, Pernambuco), Anésia Silveira (de Santa Catarina), Vitalino Filho (de Caruaru, Pernambuco) e Mestre Nosa (de Juazeiro). No documento de 1972 o critério de agrupamento foi a técnica de produção, tendo sido indicados 32 itens, dos quais apenas as 15 produções de cerâmicas receberam indicação da localidade de origem e somente as de Caruaru receberam indicação de autoria: João Ezequiel, Lauro Ezequiel, Maria das Neves e Zé Caboclo.

Outro exemplo disto encontra-se na apresentação do livro Cerâmica popular do Nordeste, publicado pela Campanha um ano após a criação do Museu de Folclore. Esta apresentação, redigida por Renato Almeida (1969: 9-13), é focada na produção de cerâmica, objeto de estudo publicado no livro. Entretanto, permitenos pensar como os folcloristas entendiam o campo da produção de artesanato e da arte popular. Para o autor, o produto artesanal mesmo tendo sido produzido por mãos diferentes, o que lhe atribui um caráter individualizado, sempre são "feit[o]s dentro de formas que representam experiência e imitação coletiva", não caracterizando um autor, mas uma região ou uma comunidade. Para eles, mesmo 
sendo encontrado nesse tipo de produção um "certo sainete individualizado", não se foge ao "sentido folclórico". 0 interessante do texto - e por extensão do livro - é que apesar de definir a arte popular como eminentemente folclórica e desvalorizar a individualidade da concepção, o autor frisa a proteção ao artista popular e o livro prioriza, não apenas o objeto e seus tipos de produção, mas os indivíduos, destacando as formas individualizadas de produção em especial dos figurativistas: Antônio Leão, Lídia, José Antônio, José Rodrigues, Zé Caboclo e Manuel Eudócio.

Renato Almeida, no relatório de atividade da Campanha de Defesa do Folclore Brasileiro, diz que é perceptível a existência de arte popular, entretanto ela ainda é tão ínfima que não merece ser estudada. Talvez seja nessa vertente que os folcloristas acreditassem e por isso não se preocupassem em individualizar a produção, destacando apenas nomes já consagrados em alguns circuitos de arte, como é o caso ícone dos ceramistas figurativos de Caruaru. Nesta vertente, ainda na apresentação do livro Cerâmica popular do Nordeste, Almeida (1969: 9) fala sobre o "grande interesse (sic) e a curiosidade crescente em torno da arte e dos artistas populares", afirmando que "os estudos de Folclore [...] não herdaram aquêle (sic) interesse dos etnógrafos pela cultura material do povo, suas artes e técnicas, enfim sua ergologia". Este interesse, entretanto, é destacado na proposta de Gustavo Barroso para a criação de um Museu Ergológico Brasileiro.

Embora as propostas de Barroso não tenham sido adotadas pelo Museu de Folclore Edison Carneiro, é interessante comparar as suas concepções de arte com as dos folcloristas que dirigiam a Campanha. Tanto um quanto outros, consideravam que esta arte representava uma expressão coletiva. Porém, enquanto Barroso a concebia como sinônimo de habilidades ou ofícios manuais, os folcloristas a distinguiam da técnica, atribuindo-lhe uma marca individualizada desde que reconhecida pela coletividade. Portanto, para os folcloristas, arte e técnica representavam coisas distintas, porém com valores equivalentes. 
Assim como os exemplos acima, a exposição de 1980 também é um reflexo do entendimento que os folcloristas tinham de Artesanato e Arte popular. 0 núcleo referente a esta temática demonstra esta tensão. É o maior e apresenta diferenciações quanto a forma museográfica e o texto do catálogo. A museografia privilegia o acervo em base, sem vitrines. 0 texto, apesar de destacar os processos artesanais e a função utilitária e/ou figurativa, não deixa de indicar vários "artesãos folclóricos". Este núcleo não cita as categorias artistas ou arte popular, trata do "artesão folclórico" e "artesanato folclórico". Esta perspectiva que a princípio parece distante dos exemplos dados acima, após algum tempo de análise, indica uma abordagem igual, já que os nomes dos artesãos folclóricos citados no texto são de artesãos ou áreas já consideradas "expoentes da criação plástica brasileira".

Não está sendo afirmando aqui que eles não privilegiassem a produção anônima, por meio do discurso da criação individual subordinada ao coletivo. Também não estamos negando afirmações, como a de Guacira Waldeck (2002), de que nas exposições não era comum os artesãos/artistas populares serem identificados. 0 que está sendo frisado é que sempre existia o espaço para a produção individualizada e que este espaço não era tão pequeno como pensamos.

Na exposição de 1980, portanto, o núcleo Artesanato estabelece uma mediação entre técnica coletiva e expressão individual aceita pela coletividade. Esta prerrogativa encontra-se inclusive na definição de artesão folclórico presente no texto de Vera de Vives.

Voltando esse debate para as exposições permanentes de 1984 e de 1994, assim como, para a versão do tesauro elaborada década de 1980 e 1990 e as publicadas em 2004 e 2006, pode-se dizer que imprimisse com clareza a abordagem no campo da arte. Nas exposições os núcleos que enfocam a técnica estão marcadamente divididos, sendo chamados de: "Homem na transformação da natureza e na 
produção da cultura” em 1984 e “Técnica” em 1994. Enquanto os núcleos referentes ao domínio da arte são denominados: “Indivíduo e Coletividade” (1984) e "Arte" (1994).

Os núcleos relacionados à Técnica, apesar de informarem os autores das peças, enfocam a relação com o meio ambiente, os produtos culturais feitos pelo homem como formas de representações dos mecanismos utilizados para propiciar sua sobrevivência, adaptação ao meio natural, demonstrando como cada grupo social acaba estabelecendo uma relação diferenciada com o meio ambiente. Os núcleos relacionados a Arte, entretanto, enfocam a capacidade de releitura, criação e expressão de determinados indivíduos dentro da coletividade e falam textualmente sobre a inserção deles "no universo da arte popular". É interessante observar que várias obras presentes na exposição de 1980 se repetiram na exposição de 1984 e 1994. A diferença dessa abordagem para a de 1980 é que os artistas, mesmo sendo parte da coletividade, são personificados, têm rosto e individualidade ressaltada.

Na versão do tesauro elaborada ao longo das décadas de 1980 e 1990 percebe-se a ampliação quantitativa dos termos antes utilizada na classificação decimal publicada por Vicente Salles. O foco central sai da habilidade, da técnica, da coletividade. $\mathrm{O}$ conceito Arte, com uma série de Termos Específicos, é incluído.

As versões do tesauro de 2004 e 2006 volta a restringir os termos ao universo do folclore e da cultura popular tradicional brasileira, mantendo, no entanto, termos associados ao universo conceitual da arte, tal como: Artista popular. Como afirma Guacira Waldeck (2002: 89), atualmente as exposições e publicações, espaços fundamentais e já bastante referenciados na individualização moderna da arte e do artista, incluem o artista popular. 
Esses termos, no entanto, não podem ser analisados isoladamente já que fazem parte de um sistema terminológico que expressa uma classificação pautada em uma rede conceitual. Para melhor visualização dessa rede, segue uma tabela e uma listagem dos termos selecionados para a análise de Artesão, Artista popular, Objeto artesanal e Técnica artesanal, com seus termos ascendentes diretos e respectivas notas de aplicação, termos genéricos, específicos e associados:

\begin{tabular}{|l|l|l|l|}
\hline Categorias conceituais & \multicolumn{3}{|l|}{ Termos presentes no Tesauro } \\
\hline Entidade & Indivíduo & Pessoa & Artesão \\
\cline { 3 - 4 } & & & Artista popular \\
\cline { 2 - 4 } & Artefato & Objeto artesanal \\
\hline Processo & Atividade produtiva & Técnica artesanal \\
\hline
\end{tabular}

Observa-se que Artesão e Artista popular são considerados Termos Específicos (TE) de Pessoa que, por sua vez, é um TE de Indivíduo. Objeto artesanal é um TE de Artefato. Técnica Artesanal é TE de Atividade produtiva. Indivíduo e Artefato integram a categoria conceitual Entidade e Atividade produtiva integra a categoria Processo. Estas categorias representam conceitos de grande abrangência e apresentam em sua estrutura diversos termos específicos.

Com a estratégia adotada de trabalhar as grandes categorias conceituais mestras dos tesauros e ter como parâmetro os acervos institucionais, pode-se dizer que nesta versão, ao contrário da versão anterior, a categoria Técnica foi mais trabalhada.

A categoria Arte não foi trabalhada como termo definido. Ela foi alvo de inúmeros debates sobre o modo como deveria ser abordada, sem que, entretanto, se tenha chegado a um consenso. Ela é vista pelas coordenadoras metodológicas e de conteúdo do projeto como uma área de conhecimento periférica, ou seja, uma categoria que não está dentro da área núcleo do Tesauro (folclore e cultura 
popular brasileira), formando-se "paralelamente ao núcleo, acrescentando a este último novos aspectos ou ainda corrigindo-os" (Jaenecke: 1994: 5 apud Pinho: 2006: 24). Isto não quer dizer que a concepção de arte não esteja presente no Tesauro, uma vez que nele se encontram termos como Artista Popular que apresentam em sua definição a ideia de inferência de marca própria e diferenciadora. Segundo Mariza Coelho (2008), a catalogação de uma publicação que aborde a arte popular é mais fácil, pois o termo escolhido será determinado pelo enfoque dado pelo autor da obra.

A indexação da informação, um dos objetivos do tesauro, por meio desses conceitos demonstra que a arte popular, assim como qualquer forma de expressão artística, faz parte de um sistema cultural (Bourdieu: 1987; Geertz: 1997) e que o critério de determinação do que é inserido em cada categoria, ou seja, os termos inclusos, os conceitos e as relações que lhes são atribuídas, aproximam-se do que Clifford (1994) define como "sistema arte-cultura". Usado no tratamento, organização e recuperação das informações, o tesauro, neste contexto, expressa e reafirma conceitos que estabelecem as fronteiras entre os termos presentes no campo da Arte Popular.

Estudar esses termos significa analisar o papel desse instrumento terminológico nas áreas de folclore e cultura popular. Embora as definições e a discussão sobre as fronteiras entre "arte" e "objeto artesanal", "técnica artesanal", "artista popular" e "artesão" expressem uma visão hierárquica e dominante, é importante ressaltar que, na perspectiva do indivíduo que exerce essa atividade, raramente a instância do trabalho manual ou mecânico ('artesanal') é separada do trabalho intelectual, possuindo ambos igual dignidade (Porto Alegre: 1985). Bourdieu (1987:159) afirma isto ao dizer que:

[...] todas as relações que uma dada categoria de intelectuais ou artistas pode instaurar com as demais categorias constitutivas da sociedade 
intelectual ou artística ou com o público externo a esta sociedade e, a fortiori, com qualquer instância social externa - quer se trate de poderes econômicos com dimensão cultural como os marchands ou os editores, de poderes políticos, e até de instâncias de consagração cultural cuja autoridade deriva seu princípio de fora do campo de produtores, a exemplo das Academias - são medidas pela estrutura do campo na medida em que dependem da posição que esta categoria particular ocupa na hierarquia que se estabelece do ângulo da legitimidade cultural no interior do campo das relações de produção e difusão dos bens simbólicos. A sociologia da produção intelectual e artística constitui seu objeto próprio e, ao mesmo tempo, seus limites, ao construir o sistema relativamente autônomo das relações de produção e circulação dos bens simbólicos.

Ao ser individualizado o artista popular se afirma como indivíduo singular na sociedade. Porém, como afirma Nobert Elias, o "indivíduo está sempre ligado à rede de relações, o que implica a regulação social de sua trajetória. 0 que é preciso levar em conta é a questão pautada entre o artista e a sociedade" (apud Zoladz 2004: 184). Sendo assim, neste contexto de múltiplos sentidos sociais, encontra-se o artista popular/artesão e sua produção, entretanto, é importante frisar que:

Os próprios artistas populares não foram absolutamente agentes passivos de seu processo de gradual reconhecimento. Pois também por seu lado experimentavam mudanças em relação ao seu meio cultural, fazendo uma sínapresentação formal própria, como qualquer outro artista, das transformações que viam acontecer diante de seus olhos e que também os motivavam. (Frota: 2005, 31)

Com a noção clara desse homem brasileiro como produtor de cultura tem um papel determinante, que dentre os produtos feitos por ele está a arte popular e que ela é um importante instrumento de pesquisa, o CNFCP procura desde 1982 uma perspectiva etnográfica, num exercício descritivos que Geertz (1978: 20) sugere como tentar ler, assume então a finalidade de descobrir a realidade - ou construir 
suas formas, tentativas, de leituras. Rosza vel Zoladz (2007) afirma que a participação social do artista, além de sua relação com o mercado e com as formas de criação, é primordial no debate sobre quem é artista? Qual a sua identidade? E qual o seu papel no imaginário brasileiro?

Pelo que se percebe o campo da arte em alguma medida sempre estiveram presentes nas exposições da instituição, sendo que, os problemas que acompanham as definições de folclore e cultura popular aparecem também no que se pretende definir como Arte Popular. À oposição arte popular/arte erudita e arte/artesanato que, embora atualmente contestada, fundamentou durante muito tempo a concepção destas formas de expressão.

Estas discussões também são recorrentes nas obras de autores como Gilberto Freire, Mário de Andrade, Luís Saia, Augusto e Aberlado Rodrigues, Clarival do Prado Valadares, Renato Almeida, Cecília Meireles, René Ribeiro, entre outros, assim como em documentos elaborados pelo então Centro Nacional de Referência Cultural, do Instituto do Patrimônio Histórico e Artístico Nacional, e por estudos desenvolvidos por pesquisadores atuais. Entretanto, Dickie (apud Gell, 2001: 176) diz que:

\footnotetext{
Uma obra pode estar, a princípio, fora do circuito oficial da história da arte, mas, se o mundo artístico coopta essa obra e a faz circular como arte, então ela é arte, porque são os representantes do mundo artístico, ou seja, artistas, críticos, comerciantes e colecionadores, que têm o poder de decidir essas questões, não a "história".
}

Desse modo, pode-se dizer que estes conceitos são categorias socialmente produzidas e sujeitas a reformulações, de acordo com o contexto histórico-cultural. Sem esquecer que entre os representantes do mundo artístico incluem-se jornalistas, museólogos, curadores, marchands, historiadores, antropólogos, folcloristas, designers, decoradores, profissionais que, em seus trabalhos, 
estabelecem hierarquias e atribuem valores estéticos e de mercado às produções artísticas assim como estabelecem formas de sua difusão. Alfred Gell (2001) destaca, no entanto, o seu valor sociológico, que ultrapassa a estética. A análise sociológica permite a compreensão da atribuição de valores que envolvem a legitimação das produções artísticas, sem os quais os artefatos não se caracterizam como objetos artísticos nem seus produtores como artistas.

É neste processo de atribuições de valores que as exposições permanentes e o Tesauro auxiliam o CNFCP a funcionar como uma "zona de contato" (Clifford: 1997), ou seja, como um espaço social marcado por diálogos provisórios onde pessoas de diferentes grupos sociais têm a oportunidade de trocar experiências com os objetos/coleções, com a equipe do museu, e também com os demais visitantes. James Cllifford ressalta que no caso dos museus "sua estrutura organizacional como coleção transforma-se numa relação viva, seja ela histórica, política ou moral: instaura-se então um outro jogo de trocas, repleto de poderes". Na compreensão dessa apresentação, incluem-se nestes parâmetros as coleções/acervos do MFEC e da BAA.

\section{As obras de Louco}

Boaventura da Silva Filho nasceu, no ano de 1932, em Cachoeira e faleceu na mesma cidade em 1992. Antes dos seus 30 anos sua principal profissão era de barbeiro, entretanto complementava sua renda familiar confeccionando cachimbos de casca de cajá. Os primeiros cachimbos eram lisos, depois passou a esculpir "uns rostos na frente do cachimbo" (Louco Filho, 2006).

Posteriormente, largou a profissão de barbeiro para esculpir blocos de madeira, respeitando a forma das raízes ou dos troncos de jacarandá, vinhático, sucupira e jaqueira - matéria-prima de sua produção -, talhando santos, orixás, anjos, cristos, batedores de atabaques, figuras bíblicas, fantásticas e míticas. Características marcantes, sempre presentes em suas obras desta fase, são as cabeças talhadas, 
cabelos em escamas, braços e pernas alongados, olhos entreabertos e narizes longos e afilados.

Segundo seu relato a Selden Rodman (apud Frota, 2005: 279), a ideia de seu nome artístico, Louco, surgiu no momento em que "pára de raspar cabeças para esculpir blocos de madeira" e seus vizinhos, por esse motivo, passaram a dizer que ele era louco. Para esses vizinhos era loucura optar pela produção de escultura em madeira como forma de renda familiar, principalmente tendo como fonte de inspiração a influência popular local europeia e africana. Porém, foi essa releitura das influências de seu meio que diferenciou sua produção ${ }^{4}$.

Todo esse contexto local é visivelmente presente nas obras de Louco. Suas obras refletem bem as múltiplas significações construídas em torno dos aspectos materiais e imateriais da vida social do município de Cachoeira, seu principal pólo de trabalho e socialização. Frota (idem), no entanto, informa que seu renome como artista teve início em 1965, quando levou suas obras para vender no Mercado Modelo, em Salvador, onde seu trabalho foi reconhecido e incentivado por nomes como Jorge Amado e Mário Cravo Jr.

Seu trabalho influenciou os demais artesãos de Cachoeira: seu filho Celestino da Silva (Louco Filho) que herdou seu apelido, o irmão Maluco (já falecido) e os sobrinhos Maluco Filho, Doidão e Bolão. Três outros filhos também seguiram esta linha de trabalho.

Treze obras de sua autoria compõem o acervo do Museu de Folclore Edison Carneiro, a saber:

\footnotetext{
${ }^{4}$ Este quadro exemplifica a fala de Arriscado Nunes (1995) que afirma que, nas últimas décadas, a transdiciplinaridade no campo dos estudos culturais tem revelado uma mudança central e decisiva no modo como as culturas são definidas e representadas e que a própria definição de cultura vem apontando para dimensões como descentralização, heterogeneidade, hibridismo, dominação e resistência, o que indica a crescente necessidade de se traduzirem conceitos que signifiquem conexão, ligação e articulação.
} 


\begin{tabular}{|l|r|l|}
\hline \multicolumn{1}{|c|}{ Denominação } & Número de tombo & \multicolumn{1}{|c|}{ Localização atual } \\
\hline Cristo & 72.46 & Reserva técnica \\
\hline Cabeça de Cristo & 74.105 & Reserva técnica \\
\hline Ceia & 74.106 & Reserva técnica \\
\hline Sant'Ana Mestra & 74.107 & Reserva técnica \\
\hline Cristo - Sorriso do Mundo & 74.110 & Reserva técnica \\
\hline Ceia & 75.106 & Exposição Permanente \\
\hline Anjo Gabriel, Anjo Belo e Adoração & 75.107 & Reserva técnica \\
\hline Painel dos Arrependidos & 75.108 & Exposição Permanente \\
\hline Cristo, São José e Nossa Senhora & 75.109 & Reserva técnica \\
\hline Oxalá Cristo Grande & 75.110 & Exposição Permanente \\
\hline Cabeça de Cristo & 75.111 & Reserva técnica \\
\hline Anjo de Candomblé & 75.112 & Exposição Permanente \\
\hline Cabeças entalhadas em raiz & 80.376 & Reserva técnica \\
\hline
\end{tabular}

A obra denominada Cristo (72.46) foi incorporada ao acervo em 1972. Segundo Livro de Tombo é uma doação da Bahiatursa (Empresa de Turismo da Bahia S/A). As demais foram doadas em 1974, conforme Termo de Cessão do Departamento de Ação Cultural/Ministério da Educação e Cultura à Campanha de Defesa do Folclore Brasileiro.

O Departamento de Assuntos Culturais cedeu, por meio desse termo, 146 peças. Várias dessas peças fizeram parte da exposição "7 brasileiros e seu universo: artes, ofícios, origens, permanências". 0 interessante dessa análise é pensar justamente sobre as peças de Louco que fizeram parte dessa exposição e posteriormente foram cedidas para o acervo da então Campanha de Defesa do Folclore Brasileiro e participou das três exposições permanentes que estudamos. Ao longo desse período, as mesmas peças participaram de discursos institucionais diferenciados.

Começaremos esta análise por meio da publicação da exposição "7 brasileiros e seu universo: artes, ofícios, origens, permanências", ou seja, pela exposição que possibilitou a aquisição dessas peças e que não foi elaborada pela Campanha de 
Defesa do Folclore Brasileiro. Sua publicação apresenta textos de Clarival do Prado Valladares, Lélia Coelho Frota, Luís da Câmara Cascudo, Luiz Felipe Baeta Neves, Luis Saia, Márcio Sampaio, Napoleão Figueiredo, Veríssimo de Melo, bem como, catálogo com dados biográficos e obras de Benedito, Dezinho de Valença, G.T.O., Louco, Maria de Beni, Nhozim e Nô Caboclo. Indica Gisela Magalhães e Irma Arestizábal como organizadoras da exposição e coordenadoras do catálogo.

A apresentação redigida por Renato Soeiro, então diretor do Departamento de Assuntos Culturais e do Instituto do Patrimônio Histórico e Artístico Nacional, cita a exposição como parte dos planos do Programa de Ação Cultural de "divulgação dos valores artísticos brasileiros" e completa:

além dos artesãos - quase todos de renome internacional -, destacam-se os artistas, cuja inquietação criadora tem-nos deixado em constante mobilidade dentro e fora do País.

Ao lado dos mestres dessa galeria, estão os folcloristas e críticos, cujo amor à obra dos primeiros construiu igual monumento em grandeza. Através de sua palavra, revela-se a herança brasileira - o seu instinto, o seu vigor, a sua raça (Magalhães; Arestizábal, 1974: 9).

É interessante verificar que a proposta da exposição e, conseqüentemente, da publicação como explicita Soeiro é conjugar as reflexões dos folcloristas e dos críticos de arte. Esta ação é demonstrada na página 12 onde se lê:

Da mesma maneira que esta exposição procura documentar a criatividade de alguns artistas de diferentes zonas do País, também os depoimentos refletem diferentes concepções dos seus autores.

Os textos não constituem uma publicação com temática preestabelecida, e sim uma tomada de conhecimento através de nossos estudiosos.

Os títulos dos textos também dizem muito. De oito títulos, seis explicitam o conceito de arte, arte popular ou artista popular. Lélia Coelho Frota apesar de não 
usar estes conceitos no título do artigo, demonstra que os aborda quando denomina seu artigo "Criação individual e coletividade", praticamente o nome atribuído ao núcleo expositivo da exposição permanente de 1984: "Indivíduo e coletividade", desenvolvido durante o período em que a autora foi diretora do então Instituto Nacional de Folclore - atual CNFCP.

Inseridos nesse contexto, os folcloristas e os críticos de arte que têm voz nessa exposição são agentes sociais que integram um sistema arte-cultura. A exposição caracteriza-se como um processo institucional e ideológico vinculados aos processos de acumulação e classificação material e simbólica de objetos. 0 Programa de Ação Cultural, por sua vez, é a instituição que articula estes processos e implementa as ações de políticas públicas. Os sete artistas representando os universos brasileiros, pelo simples fato de serem selecionados, ganham outra dimensão simbólica. Deste cinco são da região Nordeste: Pernambuco (Nhô Caboclo e Benedito), Maranhão (Nhozim), Piauí (Dezinho) e Bahia (Louco). As exceções são Minas Gerais (G.T.O.) e Goiás (Maria Beni).

Essa exposição tem como sub-título os termos: artes, ofícios, origens, permanências. Com exceção do conceito de arte, os demais são fortemente marcado nos discursos dos folcloristas. Entretanto, como explicitado anteriormente o conceito de arte não é ignorado pelos mesmos. A junção desses quatro conceitos reunidos, nessa exposição, articulam todos os parâmetros de inserção e diálogo entre os folcloristas e diversos agentes das políticas públicas voltadas aos setores artesanais. Existe sim um foco de ação de valorização maior dos folcloristas ao objeto considerado artesanal e não artístico, mas também existe a pré-disposição ao diálogo, valorização e inserção de objetos considerados "arte popular" no acervo institucional. Mas, é interessante perceber que mesmo a curadoria estando a cargo de uma arquiteta com um olhar vinculado à noção de arte, o reconhecimento de folcloristas é marcado pela inclusão dos mesmos na 
definição da linha dessa exposição, assim como a cessão das obras à Campanha de Defesa do Folclore Brasileiro.

Essas obras inclusive tornam-se estratégicas, todas as obras de Louco já são incorporadas ao acervo com autor identificado. Várias de suas obras são catalogadas com títulos, fato que atribui a ela um caráter interpretativo diferenciado do artesanato. Toda exposição permanente da instituição a partir de 1980 contam com peças suas. Mesmo no módulo Artesanato da exposição de 1980, onde foi abordado como um artesão folclórico, existe no catálogo referência a seu nome e sua produção. Ele nunca foi um artesão anônimo dentro de uma exposição. A partir das novas políticas de documentação e de exposição permanente assumida em 1982 pela instituição a acentuação do individual e artístico em paralelo ao coletivo se acentuou.

\section{Paralelos entre termos do Tesauro e das exposições permanentes do CNFCP em relação as obras de Louco}

Em um paralelo com as definições dos termos do Tesauro de Folclore e Cultura Popular Brasileira, Louco mesmo quando definido a exposição permanente como Artesão folclórico explicitava o que hoje está definido como Artista popular, pois naquele momento Vera de Vives que escreveu o texto considerado catálogo da exposição já inferia marcas próprias e diferenciadoras ao trabalho desse artista. É interessante perceber neste caso que já naquela época, na qual tão corriqueiramente diz-se que os folcloristas não valorizavam essa dimensão, percebe-se no texto do catálogo da exposição esta ênfase. 0 "artesanato folclórico" exposto não valorizava apenas a técnica, o ofício, mas também as marcas próprias, a individualidade.

Caso o paralelo seja feito com o vocabulário controlado da Biblioteca Amadeu Amaral publicado por Vicente Salles também se pode visualizar esta ênfase: a 
classe 398.6 Artes e Técnicas, a categoria Arte esta marcadamente junto a Técnica e engloba, entre outros, os diferentes tipos de artesanato.

Continuando nesse paralelo com base nos demais termos do Tesauro, podem-se estabelecer diversos relacionamentos entre as questões de individualização e coletividade. Restringindo essa meta às análises aqui propostas destacam-se quando se documenta ou expõe as obras de Louco termos como Atividade produtiva, Técnica artesanal e Entalhe, Artefato, Objeto artesanal e Escultor.

Atividade produtiva inclui não apenas as atividades de ordem econômica, mas também as de ordem "social e/ou cultural que se configura pela produção de bens ou utilidades para satisfazer as necessidades humanas". Cruzando esta definição com a de Técnica artesanal verifica-se que esta necessidade também "pode ter finalidade [...] artística”. 0 termo Entalhe é aqui incluído por ser a técnica artesanal "que consiste em esculpir [...] madeira", ou seja, a dominada por Louco. Ao último está diretamente relacionado o termo Escultor que é a pessoa que domina esta técnica.

Artefato no Tesauro caracteriza-se como "forma individualizada de cultura material”, na qual se inclui o Objeto artesanal - "a forma não individualizada, que escapa a produção em série, oriundo de um saber advindo da tradição e vivência do indivíduo em seu grupo". Objeto artesanal aqui tem um caráter tanto de tradição coletiva como de individualidade.

Marcadamente se Louco continua-se a produzir cachimbos como no início da sua carreira, hoje provavelmente ele estaria dentro da categoria artesão e não de artista popular. Foi sua releitura de seu contexto e o reconhecimento a ele atribuído por um grupo de intelectuais que ofereceu a este indivíduo um espaço no domínio da arte popular. 
Neste contexto, pode-se dizer que os problemas que acompanham as definições de folclore e de cultura popular aparecem também no que se define como, Objeto artesanal, Técnica artesanal, Artesão e Artista popular. Nesta perspectiva, pode-se observar a presença de diferentes concepções das categorias Folclore, Cultura popular, Arte, Técnica, Arte popular, Artesão, Artista popular, Objeto Artesanal, além das de Patrimônio e Mercado. Todas essas categorias são portadoras de conteúdos simbólicos que se expressam nos sistemas de classificação, colecionismo e exposição interesses culturais, políticos, econômicos.

Essas categorias aparecem no campo discursivo com vários significados, remetendo a diferentes formas de valoração e a novas qualificações. As narrativas construídas a partir dessas categorias possuem um caráter dinâmico e implicam em diferentes modos de classificação, de acordo com o contexto e projetos políticos de cada momento. No caso em questão, pode-se dizer que um dos principais objetivos do CNFCP, ao longo de sua história, foi direcionar o olhar para determinadas referências tradicionais da cultura popular, exaltando seus valores simbólicos.

Em todos os momentos, os argumentos utilizados para legitimar o que deveria ser considerado como pertencente ao âmbito da arte ultrapassavam a materialidade e a estética do objeto, investindo-o de uma aura criativa, poética e informativa, assinalando a presença de algo diferencial. Isto demonstra que, apesar de pouco divulgadas, existem singularidades nos discursos sobre o campo da arte nas narrativas elaboradas pelos folcloristas e antropólogos.

De modo geral, a adequação do antigo INF a uma perspectiva antropológica é considerada uma ruptura conceitual com as políticas e ações até então vigentes. No entanto, percebe-se que a maioria das ações subsequentes são, muitas vezes, desdobramentos ou revisões daquelas vigentes no período em que os folcloristas estiveram à frente da instituição. Estes desdobramentos, entretanto, não significam 
uma evolução linear de concepções e práticas de classificação, coleção e exposição sobre folclore e cultura popular brasileira, mas campos de conflito, de (des)estabilizações e de reafirmação dos grupos de intelectuais e profissionais que dirigiram a instituição.

Os folcloristas, ativos à frente da instituição até 1982, foram agentes fundamentais do processo de reconhecimento do folclore. Um dos seus objetivos era indicar os indivíduos e grupos, cujos conhecimentos tradicionais deveriam ser reconhecidos como componentes da identidade nacional. Deste modo, embora reconhecessem a dimensão da criação artística, não a tinham como "carro chefe" de suas ações, pois seu foco estava centrado no que era visto como conhecimento coletivo e nas manifestações consideradas valores do espírito.

Os museólogos e antropólogos ampliaram o paradigma que até então havia orientado os modos de pensar e agir da instituição e estabeleceram novas diretrizes para a construção do sistema classificatório e para a concepção das exposições. Sob este novo olhar, a narrativa que pressuponha uma identidade nacional homogênea foi desconstruída, dando lugar a uma abordagem que privilegiava a diversidade cultural. Um dos reflexos dessa nova abordagem foi a valorização da cultura material como foco de ação institucional e a construção de novas narrativas sobre arte nas quais se valorizava a autoria, a criação e a individualidade.

Mais uma vez, não se pode dizer que esta mudança de foco está restrita ao período posterior a 1982, pois durante o período da Campanha de Defesa do Folclore Brasileiro o foco já havia sido ampliado das linguagens musicais para os folguedos e no período seguinte o então Instituto Nacional de Folclore ampliou os estudos e as ações para o campo da cultura material, porém ainda muito ligada às categoria artesanato e técnica. 
É interessante observar que esta valorização do artesanato tradicional não se dá somente nesta instituição. Vários outros programas governamentais, sobretudo na esfera federal e estadual, foram criados ao longo dos anos. Um dos principais intuitos desses programas é geração de renda e melhoria de qualidade de vida dos produtores por meio da inserção de seus produtos em um mercado mais amplo. Para isso, oferecem aos artesãos suporte para produção, difusão de saberes, divulgação, comercialização, gestão e associativismo. Nestes programas, de modo geral, não se faz distinção entre artesanato e arte popular, considerando-se os dois termos como equivalentes. É importante destacar que nas exposições e no Tesauro estes termos não são utilizados como equivalentes. Sua base conceitual, perpassada por um discurso institucionalizado e acadêmico, tem o propósito de valorizar a arte popular e o artesanato de cunho tradicional.

\section{REFERÊNCIAS}

ALMEIDA, Renato. Apresentação. In: BORBA FILHO, Hermilo e RODRIGUES, Abelardo (org.). Cerâmica popular do Nordeste. Coleção Folclore Brasileiro. Rio de Janeiro: MEC/Campanha de Defesa do Folclore Brasileiro, 1969.

BARROSO, Gustavo. Museu ergológico brasileiro: o desenvolvimento dos estudos folclóricos em nosso país. Um esquema ergológico e outras notas. Anais do Museu Histórico Nacional. V. 3. Rio de Janeiro: Imprensa Nacional, 1945.

BOURDIEU, Pierre. A economia das trocas simbólicas. São Paulo: Perspectiva, 1987.

CARTA do folclore brasileiro. In: Congresso Brasileiro de Folclore (1.:1951). Anais... Rio de Janeiro: Ministério das Relações Exteriores, 1952, v.1, p. 77-85.

CENTRO Nacional de Folclore e Cultura Popular. Tesauro de Folclore e Cultura popular. Rio de Janeiro: CNFCP/IPHAN/MinC; Brasília: Unesco, 2004. (Cd-rom)

CENTRO Nacional de Folclore e Cultura Popular. Tesauro de Folclore e Cultura popular. Rio de Janeiro: CNFCP/IPHAN/MinC e Caixa Econômica Federal; Brasília: Unesco, 2006. (Cd-rom)

CLIFFORD, James. Colecionando Arte e Cultura. Revista do Patrimônio Histórico e Artístico, 23 (Cidade), Rio de Janeiro: IPHAN, 1994. pp. 69-89.

CLIFFORD, James. Museums as Contact Zone. In: Routes: Travel and Translation in the late twentieth century. Cambridge, Harvard University Press, 1997.

DUVIGNAUD, Jean. 0 artista, a arte e a identidade. Palestra editada com apoio do Fórum de Ciência e Cultura. Tradução de Rosza vel Zoladz. Rio de Janeiro: UFRJ/EBA, 1994. 
FROTA, Lélia Coelho. Pequeno Dicionário da Arte do Povo Brasileiro - Século XX. Rio de Janeiro: Aeroplano, 2005.

GEERTZ, Clifford. A arte como um sistema cultural. In: $O$ saber local: novos ensaios em antropologia interpretativa. Petrópolis: Vozes, 1997.

GEERTZ, Clifford. A interpretação das Culturas. Rio de Janeiro: Zahar, 1978.

GELL, Alfred. A rede de Vogel: armadilhas como obras de arte e obras de arte como armadilhas. In: FERREIRA, Glória; VENANCIO FILHO, Paulo (org). Arte \& Ensaios n. 8. Rio de Janeiro: PPGAV/Eba/UFRJ, 2001. pp. 174-191.

MAGALHÃES, Gisela; ARESTIZÁBAL, Irma (Orgs.). 7 brasileiros e seu universo.

MENDONÇA, Elizabete. Tesauro e exposições permanentes de folclore e cultura popular: narrativas sobre arte popular elaboradas pelo Centro Nacional de Folclore e Cultura Popular (1980-2004[2006]). Rio de Janeiro: UFRJ, Programa de Pós-Graduação em Artes Visuais/Escola de Belas Artes, 2008. (Tese de doutorado)

NUNES, J. Arriscado. Boundaries, Margins and Migrants: on paradigmshifts, heterogenity and culture wars. Coimbra: Centro de Estudos Sociais, ago. 1995.

PINHO, Fabio Assis. Aspectos éticos em representação do conhecimento: em busca do diálogo entre Antonio García Gutiérrez, Michèle Hudon e Clare Beghtol. São Paulo: Marília, 2006. Dissertação (mestrado) - Universidade Estadual Paulista, Faculdade de Filosofia e Ciências.

PORTO ALEGRE, Maria Silvia. A arte e ofício de artesão: história e trajetória de um meio de sobrevivência. Águas de São Pedro, 1985. Trabalho apresentado no IX Encontro Anual da ANPOCS, 22-25 out.

SALLES, Vicente. Classificação decimal de Folclore. Revista Brasileira de Folclore, ano 7, n 19, pp. 265-293. Rio de Janeiro: Campanha de Defesa do folclore Brasileiro. Dezembro1967.

WALDECK, Guacira. Vitalino como categoria cultural: um estudo antropológico sobre as classificações da obra de Vitalino Pereira dos Santos, Mestre Vitalino. Rio de Janeiro: UFRJ/IFCS, 2002. (dissertação de mestrado)

ZOLADZ, Rosza vel. Resenha. Éloge de l'individu. Rio de Janeiro: EBA / UFRJ, 2004.

ZOLADZ, Rosza vel. 0 artista em meio à arte e o indivíduo: trilhas periféricas no imaginário brasileiro In: Revista Z Cultural. Rio de Janeiro: PACC/UFRJ, 2007. Disponível em: http://www.pacc.ufrj.br/z/ano3/02/rosza.htm acesso em: 17 jun. 2007.

\section{Entrevistas}

COELHO, Marisa Cônago. Marisa Cônago Coelho (Entrevista concedida para esta tese). Rio de Janeiro, maio de 2008.

SILVA, Celestino Gama da. Celestino Gama da Silva - Louco Filho (Entrevista concedida para esta tese). Rio de Janeiro, novembro de 2006. 


\section{Guias de Exposição}

Folder da Campanha de Defesa do Folclore Brasileiro: inauguração da sede: agosto de 1975. Ministério da Educação e Cultura, DAC.

Folder da Exposição Permanente do Museu de Folclore Edison Carneiro inaugurada em 1984. Ministério da Cultura, Funarte, INF.

Guia da Exposição Permanente do Museu de Folclore Edison Carneiro inaugurada em [1987?]. Ministério da Cultura, Funarte, INF.

Guia da Exposição Permanente do Museu de Folclore Edison Carneiro inaugurada em 2004. Ministério da Cultura, Funarte, INF. 